\title{
Human fear reconsolidation and allelic differences in serotonergic and dopaminergic genes
}

\author{
T Agren ${ }^{1}$, T Furmark ${ }^{1}$, E Eriksson ${ }^{2}$ and M Fredrikson ${ }^{1}$
}

Fear memory persistence, central for the development and maintenance of anxiety disorders, is partially genetically controlled. Recently, consolidation and reconsolidation processes have been reported to affect fear memory stability and integrity. This study explored the impact of reconsolidation processes and genetic make-up on fear reacquisition by manipulating reconsolidation, using extinction performed outside or inside a reconsolidation interval. Reacquisition measured by skin conductance responses was stronger in individuals that extinguished outside $(6 \mathrm{~h})$ than inside $(10 \mathrm{~min})$ the reconsolidation interval. However, the effect was predominantly present in val/val homozygotes of the functional val158met polymorphism of the catechol 0-methyltransferase (COMT) enzyme and in short-allele carriers of the serotonin-transporter length 5-HTTLPR polymorphism. These results demonstrate that reconsolidation of human fear memory is influenced by dopamine and serotoninrelated genes.

Translational Psychiatry (2012) 2, e76; doi:10.1038/tp.2012.5; published online 7 February 2012

\section{Introduction}

The acquisition and extinction of fear memories are crucial for the aetiology and symptomatology of anxiety disorders like post-traumatic stress disorder. ${ }^{1,2}$ Recently, it has been demonstrated that consolidation and reconsolidation processes affect stability and durability of fear memories. A memory is initially labile and consolidate over time to a more stable form. ${ }^{3}$ It is hypothesized that when a fear memory is reactivated, it is again transformed to a labile state, and the following stabilization is termed reconsolidation. Moreover, it is argued that during reconsolidation, memories can be updated to incorporate new information. Previous studies confirm that pharmacologically disrupted reconsolidation processes affect behaviour both in animals ${ }^{4}$ and humans. ${ }^{5-7}$ Most reconsolidation studies have used fear conditioning, the process where a fear memory is formed by repeated pairing of a neutral stimulus with an aversive unconditioned stimulus (UCS), subsequently leading to an aversive reaction to the neutral stimulus. Thus, the neutral stimulus becomes a conditioned stimulus $(\mathrm{CS}+)$. The conditioned reactions to $\mathrm{CS}+$ can be weakened or abolished with extinction training, that is, by exposure to CS + without UCS, but generally return with the passage of time (spontaneous recovery). Using extinction training during the reconsolidation phase in rodents, it has been demonstrated that reconsolidation of an activated fear memory can be influenced also nonpharmacologically in a way that permanently attenuate the fear memory. ${ }^{8}$ In this vein, Schiller et al. ${ }^{9}$ concluded that the return of fear reactions in humans was weakened when a previously reinforced stimulus was presented $10 \mathrm{~min}$, but not $6 \mathrm{~h}$ before extinction training, that is inside, but not outside, of the reconsolidation interval.

In Schiller study, ${ }^{9}$ subjects completed a fear-conditioning procedure to experimentally induce a fear memory. Twenty-four hours after the initial conditioning session, subject returned and the fear memory was activated by a 2-min presentation of the $\mathrm{CS}+$ in the absence of UCS. One group received extinction training 10 min after the fear memory activation and hence, early during the reconsolidation process. The other group received extinction training $6 \mathrm{~h}$ after the fear memory activation, hence after completion of reconsolidation. Another $24 \mathrm{~h}$ later, spontaneous recovery of fear was tested in a second extinction session. The results showed that the group given extinction training during the reconsolidation interval (i.e., $10 \mathrm{~min}$ after memory activation) exhibited less fear, as reflected by skin conductance response (SCR), when exposed to $\mathrm{CS}+$, than the group that received extinction training $6 \mathrm{~h}$ after the memory activation. The effect of the manipulation lingered even after 1 year when the return of fear was tested with reinstatement, a process where extinguished responses reappear to $\mathrm{CS}+$ after unpaired UCS presentations.

Anxiety disorders wax and wane: In post-traumatic stress disorder, for example, cues associated with trauma may repeatedly reactivate symptoms instigated by a single traumatic event. In addition, the remission rate after treatment is incomplete, because symptom reactivation occurs. ${ }^{10}$ Hence, it is clinically motivated to study if reconsolidation processes influence not only the subsequent expression, but also the reacquisition of fear. In fear conditioning, reacquisition is a second session of fear conditioning performed to investigate how earlier manipulations of the memory affects a relapse into renewed fear expression for the conditioned stimulus.

Fear conditionability is a heritable characteristic ${ }^{11}$ influenced by individual differences in serotonin- and dopaminerelated polymorphisms. In particular, short-allele (s) carriers

\footnotetext{
1Department of Psychology, Uppsala University, Uppsala, Sweden and ${ }^{2}$ Department of Pharmacology, University of Gothenburg, Gothenburg, Sweden Correspondence: T Agren, Department of Psychology, Uppsala University, Box 1225, Uppsala SE-751 42, Sweden.

E-mail: thomas.agren@psyk.uu.se

Keywords: dopamine; fear conditioning; genes; memory reconsolidation; polymorphism; serotonin

Received 20 October 2011; revised 20 December 2011; accepted 8 January 2012
} 
of the serotonin-transporter gene-linked polymorphic region (5-HTTLPR) display stronger acquisition and slower extinction compared with long-allele (II) homozygotes. ${ }^{12-14}$ Moreover, 5-HTTLPR has been associated with anxiety-related personality traits, ${ }^{15}$ development of psychopathology ${ }^{16}$ and enhanced reactivity of the amygdala, ${ }^{17}$ a key structure for fear conditioning, ${ }^{18}$ suggesting a possible link between fear memory processes, psychopathology and serotonergic neurotransmission.

Animal experiments provide evidence that dopamine also impacts fear acquisition, ${ }^{19}$ extinction $^{20}$ and consolidation. ${ }^{21}$ Catechhol-O-methyltransferase (COMT) is an enzyme vital to the elimination of dopamine in prefrontal areas and the functional polymorphism val158met (rs4680), where the val allele is associated with higher COMT activity, ${ }^{22}$ enables an indirect way to study dopaminergic effects throughout the brain. Two studies have related fear conditioning to the COMT val158met genotype in humans, but with mixed findings. Lonsdorf et al. ${ }^{14}$ noted slower extinction in met homozygotes, whereas Razcka et al. ${ }^{23}$ noted stronger reacquisition in a val/ met-group, but only in the presence of a certain dopamine transporter (DAT1) polymorphism.

As monoaminergic genetic polymorphisms modulate fear conditioning and as reconsolidation influence fear expression, the present study investigated if serotonin- and dopaminerelated polymorphisms also affect reconsolidation. To these aims, the present study utilized the non-pharmacological human reconsolidation disruption effect reported by Schiller et al. ${ }^{9}$ to study reacquisition of human fear indexed by SCRs. The a priori hypotheses were that extinction inside as compared to outside the reconsolidation interval should compromise reacquisition and that monoaminergic genes would modulate the effect. In addition, a previously reported $^{5,9}$ reconsolidation effect for reinstatement was predicted.

\section{Materials and methods}

Participants. A total of 66 participants (38 females, age: mean \pm s.d. $=24.6 \pm 4.0$ ) recruited by public advertisements were randomly assigned to one of two groups. In one group, extinction was given inside (10 $\mathrm{min})$, and in the other group, outside $(6 \mathrm{~h})$ the reconsolidation interval after a 2-min fear memory reminder. Two subjects were excluded due to technical difficulties. Subjects received SEK 400 for participation.

\section{Materials}

Stimuli. Stimuli were projected on a $17^{\prime \prime}$-computer screen using E-prime 2.0. (Psychology Software Tools, Pittsburgh, PA, USA) and consisted of a photo of a neutral environment containing a lamp that was lit either in red or blue. One colour was paired with UCS and became the CS + , whereas the other colour was unpaired (CS-). The CS colour was counterbalanced across subjects. Each stimulus was shown for $6 \mathrm{~s}$ with 14-s intervals between trials when the environment was displayed with the lamp unlit. A 500-ms mild electric shock was delivered $250 \mathrm{~ms}$ before the $\mathrm{CS}+$ ended.
Psychophysiology equipment. The electric shocks were administered by PsychLabs SHK 1 pain stimulator (Psychlab, Cambridge, MA, USA) and had a maximum strength of $5 \mathrm{~mA}$. Electrodes (EL124), prepared with electrolyte medium to facilitate shock conduction were attached with surgical tape to the dorsal right-lower arm of the participants. The SCRs were measured in microsiemens with the Psychlab 24-bit Skin Conductance System, using two $8-\mathrm{mm} \mathrm{Ag} / \mathrm{AgCl}$ electrodes filled with isotonic electrolyte gel attached to the hypothenar eminence of the left hand. ${ }^{24}$

Genotyping. The 5-HTTLPR polymorphism in the promoter of the serotonin transporter gene was amplified using the PCR primers 5'-ATGCCAGCACCTAACCCCTAATGT-3' and 5'-GGACCGCAAGGTGGGCGGGA-3' yielding a product of $419 \mathrm{bp}$ for the 16-repeat allele (I) and $375 \mathrm{bp}$ for the 14-repeat allele (s). After an initial denaturation step of $15 \mathrm{~min}$ at $95^{\circ} \mathrm{C}$, 35 cycles were performed, including $30 \mathrm{~s}$ at $95^{\circ} \mathrm{C}, 30 \mathrm{~s}$ at $66^{\circ} \mathrm{C}$, and an elongation step at $72^{\circ} \mathrm{C}$ for $1 \mathrm{~min}$. Genotyping was performed on $2 \%$ agarose gels. DNA was visualized by ethidium bromide. Short-allele carriers $(n=46)$ were grouped together and later compared with homozygotes of the long allele $(n=16) .^{15,17}$ For two subjects, the gene analysis failed to extract the 5HTTPLR genotype.

The val/met polymorphism in the gene encoding COMT was analysed using the $\mathrm{ABI} 7900 \mathrm{HT}$ instrument with a TaqMan assay in accordance with the protocol from the manufacturer (Applied Biosystems, Foster City, CA, USA). Given the functionality of the polymorphism, ${ }^{25}$ homozygotes of the val allele $(n=15)$ were grouped together and later compared with carriers of the met allele $(n=46)$. Gene analysis failed for three of the subjects.

\section{Procedure}

Day 1. Participants signed informed consent and determined the strength of the unconditioned electric shock by following the instruction that it should be unpleasant, but endurable. They then underwent an acquisition session in which 16 $\mathrm{CS}+$ and $16 \mathrm{CS}-$ were presented in a random order, with the limitation that no stimulus type was repeated more than two times in a row. CS + was always paired with UCS. After the session, subjects were asked if they identified a stimulus contingency and if so, asked to describe it. They rated the experienced distress of the experimental procedure on a scale from 1 to 10, with one indicating 'not distressful' and 10 denoting 'very distressful'.

Day 2. Twenty-four hours after acquisition, the participants returned, electrodes were attached in the same way and the $\mathrm{CS}+$ reminder was shown for $2 \mathrm{~min}$ to facilitate memory activation. One group then received extinction $10 \mathrm{~min}$ after the memory activation (the 10-min group), whereas the other group received extinction after $6 \mathrm{~h}$ (the 6 -h group). Extinction consisted of eight presentations of $\mathrm{CS}+$ and CS- each. Shock electrodes were applied, but no shock was administered. 
Day 3. Twenty-four hours after completing extinction, participants returned for reinstatement and reacquisition. Reinstatement consisted of four presentations of CS + and CS- each, with four pseudorandom shocks administered within inter-trial intervals of about $30 \mathrm{~s}$. Reacquisition consisted of four presentations of $\mathrm{CS}+$ and $\mathrm{CS}-$ each. $\mathrm{CS}+$ was always, and CS- never paired with a shock. Regrettably, due to a programming error, reinstatement data were compromised and could not be retrieved for all participants. Participants left a saliva sample for DNA analysis, using an Oragene DNA Genotek saliva sample container (DNA Genotek, Ottawa, Ontario, Canada).

Analyses. Stimulus-induced SCRs were calculated by taking the maximum of the skin conductance deflection in the 1.5-5.75-s interval after stimulus onset subtracted by the immediate preceding baseline. ${ }^{26}$ Thus, for CS + , the endpoint of the scoring interval coincided with UCS onset. All SCRs were range-corrected by dividing each reaction for every individual with that individual's maximum deflection (irrespective of stimuli and experimental phase). ${ }^{27}$

$\mathrm{CS}+(0.23 \pm 0.02)$ elicited greater responses than $\mathrm{CS}-$ $(0.13 \pm 0.01) ; \mathrm{t}(63)=6.25 P<1 \times 10^{-5}$. However, because data from participants that do not acquire a fear memory cannot be used to study reconsolidation processes, these subjects were excluded from further analyses. To distinguish those who did not acquire a conditioned reaction from those who did, every individual's 16 reactions to $\mathrm{CS}+$ and CS- during acquisition were ordered in pairs, and 16 delta scores were calculated as follows: $\mathrm{CS}+{ }_{1}-\mathrm{CS}_{-}{ }_{1}, \mathrm{CS}+{ }_{2}-$ $\mathrm{CS}-{ }_{2} \ldots \mathrm{CS}+{ }_{16}-\mathrm{CS}-{ }_{16}$. The average delta scores were tested against zero, using a one-tailed $t$-test with a statistical cutoff of $P<0.10$ as the within-subject conditioning criterion.

To evaluate fear conditioning, extinction, reinstatement and reacquistion, mean values of all $\mathrm{CS}+$ and $\mathrm{CS}-$ trials, as well as a delta score (CS + minus CS-) were calculated for each experimental phase (acquisition, extinction, reinstatement and reacquisition) and individual, respectively. These values were used in further analyses.

\section{Results}

Reacquisition. During reacquisition, the 6-h group $(n=15)$ discriminated $\mathrm{CS}+$ from $\mathrm{CS}-, \mathrm{t}(14)=2.18, \quad P=0.05$, demonstrating relearning, whereas the 10-min group $(n=18) \quad$ did not, $\mathrm{t}(17)=-1.42, \quad P=0.17$, reflecting the absence of relearning, together resulting in a significant group ( $6 \mathrm{~h}$ vs $10 \mathrm{~min}) \times$ stimulus (CS + vs $\mathrm{CS}-$ ) interaction $(\mathrm{F}(1,31)=7.15, P=0.01$; see Figure 1). Moreover, the reactions to $\mathrm{CS}+$ were stronger in the 6-h group than the 10min group, $\mathrm{t}(31)=1.94, P=0.03$, whereas the reactions to $\mathrm{CS}$ - were not, $\mathrm{t}(31)=0.01, P=0.99$. The two groups did not differ in acquisition (CS + minus $C S-) \mathrm{t}(31)=0.23, P=0.82$, extinction (CS + minus CS - ) $\mathrm{t}(31)=0.30, P=0.76$, or $\max$ SCR $\mathrm{t}(31)=-0.36, P=0.72$ (6-h group mean \pm s.e.m. $=$ $0.63 \pm 0.14 \mu \mathrm{s} ; 10$-min group mean \pm s.e.m. $=0.69 \pm 0.11 \mu \mathrm{s}$ ). See Supplementary Table 1 for acquisition, extinction and reacquisition data and Supplementary Table 2 for an analysis of variance (ANOVA) summary.

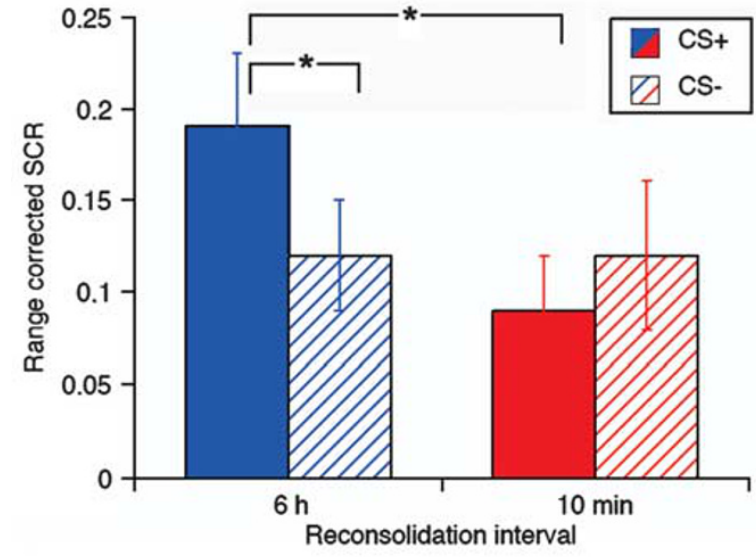

\begin{tabular}{llll}
\hline & Day 1 & Day 2 & Day 3 \\
\hline $6 \mathrm{~h}$ group & Acquisition & Reminder $\underset{\mathrm{6h}}{\stackrel{6}{\longrightarrow} \text { Extinction }}$ & Reacquisition \\
\hline 10 min group & Acquisition & Reminder $\underset{10 \mathrm{~min}}{\longrightarrow}$ Extinction & Reacquisition \\
\hline
\end{tabular}

Figure 1 Extinction during reconsolidation attenuates reacquisition of fear. Mean range-corrected skin conductance responses (SCR) to the reinforced (CS + ) and non-reinforced (CS-) cue during reacquisition day 3 . Significant discrimination was evident in the 6-h group that extinguished outside of the reconsolidation interval, but not in the 10-min group that extinguished inside the reconsolidation interval, resulting in a significant group ( $6 \mathrm{~h}$ vs $10 \mathrm{~min}) \times$ stimuli $(\mathrm{CS}+\mathrm{vs} \mathrm{CS}-$ ) interaction (top panel). Error bars are s.e.m. Asterisks indicate significant differences. Experimental design and timeline (bottom panel).

To evaluate the gene $\times$ group interaction, separate ANOVAs were performed for 5-HTTLPR and COMT, respectively, revealing gene (s vs $\mathrm{Il}$, or val/val vs met) $\times$ group $(6 \mathrm{~h}$ vs $10 \mathrm{~min}$ ) interactions both for 5-HTTLPR $\mathrm{F}(1,28)=10.77$, $P=0.003$, and COMT $F(1,28)=10.08, P=0.004$. Followup $t$-tests for 5-HTTLPR revealed that short-allele carriers extinguishing outside compared with inside the reconsolidation interval demonstrated stronger reacquisition, $\mathrm{t}(21)=4.07, P<0.001$, whereas long-allele homozygotes did not, $\mathrm{t}(7)=-1.58, P=0.16$. Moreover, within the $6-\mathrm{h}$ group, short-allele carriers displayed reacquistion than along-allele homozygotes, $\mathrm{t}(12)=2.54, \quad P=0.03 \quad$ (see Figure 2 top panel, Supplementary Tables 3 and 4 for data summaries and Supplementary Table 5 for an ANOVA summary). Similarly, follow-up $t$-tests regarding the val158met COMT polymorphism revealed that val/val homozygotes, which extinguished outside compared with inside the reconsolidation interval demonstrated stronger reacquisition, $\mathrm{t}(6)=3.03, P=0.02$, whereas met carriers did not, $\mathrm{t}(22)=1.00, P=0.33$. Within the 6 -h group, val/val homozygotes displayed stronger acquisition than the met carriers, $\mathrm{t}(13)=3.00, P=0.01$ (see Figure 2 bottom panel, Supplementary Tables 6 and 7 for data summaries and Supplementary Table 8 for an ANOVA summary).

Regarding the 5-HTTLPR groups, short-allele carriers $(n=23)$ and long-allele homozygotes $(n=9)$ did not differ in acquisition, $\mathrm{t}(30)=1.10, P=0.28$ (Supplementary Tables 3 and 4 ), but short-allele carriers displayed increased resistance to extinction as compared with the II homozygotes, $\mathrm{t}(30)=3.87, P<0.001$. To explore if extinction differences mediated the reconsolidation effect, a group $(6 \mathrm{~h}$ vs 

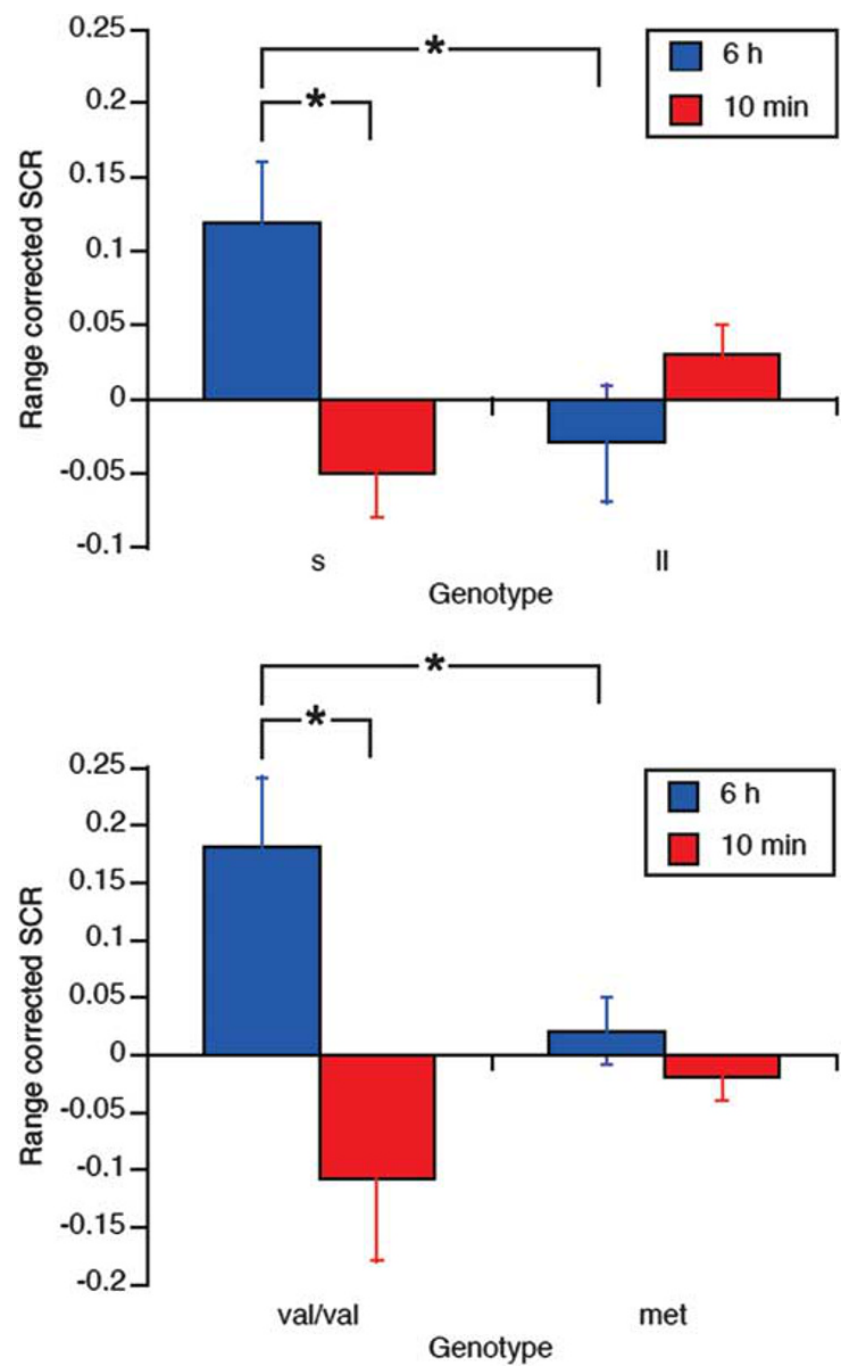

Figure 2 The reconsolidation effect on reacquisition is modulated by genes. Mean differential skin conductance delta scores (CS + minus CS-) during reacquisition of fear after extinction inside $(10 \mathrm{~min})$ and outside of $(6 \mathrm{~h})$ the reconsolidation interval in short allele carriers (s) and long-allele (II) homozygotes of the serotonin-transporter length 5-HTTLPR polymorphism (top panel), and the val/ val homozygotes and met carriers of the functional val158met polymorphism of the catechol 0-methyltransferase (COMT) enzyme (bottom panel). Error bars are s.e.m. Asterisks indicate significant differences.

$10 \mathrm{~min}$ ) $\times 5$-HTTLPR (s vs II) analysis of covariance with extinction strength ( $\mathrm{CS}+$ minus $\mathrm{CS}-$ ) as the covariate was performed. The group $\times 5$-HTTLPR interaction effect was still significant, $F(1,27)=10.31, P=0.003$, suggesting that extinction is unrelated to the reconsolidation effect (Supplementary Table 9).

Regarding the val158met COMT polymorphism groups, there was a trend towards better acquisition in the val/val homozygotes $(n=8)$ as compared with the met carriers $(n=24), \mathrm{t}(30)=-1.88, P=0.07$, but no difference in extinction, $\mathrm{t}(30)=-0.57, P=0.57$ (Supplementary Tables 7 and 8). To explore if the trend towards better acquisition among the $\mathrm{val} / \mathrm{val}$ homozygotes affected the reconsolidation effect, a group ( $6 \mathrm{~h}$ vs $10 \mathrm{~min}) \times \mathrm{COMT}$ (val/val vs met) analysis of covariance with acquisition ( $\mathrm{CS}+$ minus $\mathrm{CS}-$ ) as the covariate was performed. The Group $\times$ COMT interaction was still significant, $F(1,27)=9.50, P=0.005$, suggesting that acquisition strength is unrelated to the reconsolidation effect (Supplementary Table 10). There were not enough subjects to perform a 5-HTTLPR $\times$ COMT-polymorphism ANOVA due to the genotype partition over subjects (Supplementary Table 11).

Reinstatement. Because of a programming error, the reinstatement data were compromised for most subjects. However, data retrieved from a minority of subjects revealed a trend towards a Group effect for delta scores (CS + minus CS- $), \mathrm{t}(9)=1.42, \quad(P=0.09$ one-tailed $)$, suggesting that the 6-h group displayed more persistant fear memory than the 10-min group. This effect was mediated by $\mathrm{CS}+$ responsivity, because the groups differed in response to $\mathrm{CS}+\mathrm{t}(9)=1.77, \quad(P=0.05$ one-tailed $), \quad$ but not $\mathrm{CS}-$ $\mathrm{t}(9)=0.17, P=0.87$ (Supplementary Table 12). There were too few subjects for gene effects to be evaluated.

All principal results reported for range-corrected SCRs remained significant, also using untransformed data. A total of 62 out of the 64 subjects who completed acquisition reported contingency awareness, and as so few failed to report this, no comparisons between contingency aware and unaware subjects were performed. Accompanying differences in shock strength or distress ratings ( $P^{\prime} \mathrm{s}>0.60$; see Supplementary Table 13) were not demonstrated for any of the comparisons reported above (6h vs $10 \mathrm{~min}$, s vs II, and val/val vs met). Participants that did acquire conditioning were not different with aspect to genetic make-up from those that did not (Supplementary Table 14).

\section{Discussion}

The present study demonstrates that reconsolidation disruption not only affect spontaneous recovery and reinstatement of fear as previously reported, ${ }^{9}$ but also reacquisition, and that genetic make-up modulate the reconsolidation effect. Carriers of the short allele (but not the Il-homozygotes) of the serotonin-transporter length polymorphism (5-HTTLPR) and homozygotes of the val allele (but not met carriers) in the dopamine-related COMT val158met polymorphism demonstrated enhanced reacquisition after extinction outside, but not inside of, the reconsolidation window. This indicates that allelic differences modulate fear memory reconsolidation. Carriers of the met allele and long-allele homozygotes did not display reacquisition regardless of reconsolidation conditions, suggesting that different allele carriers may have different reconsolidation windows. Theoretically, it is also possible that long-allele and met alleles are associated with enhanced extinction retention. However, analyses evaluating the effect of extinction as related to reacquisition does not support that extinction differences are mediating the effect of reconsolidation disruption. This pattern indicates that allelic differences modulate fear memory reconsolidation in a complex way. Interestingly, the polymorphisms involved are also linked to fear conditioning, ${ }^{13,14}$ as well as psychiatric disorders of the affective spectrum, ${ }^{28}$ suggesting a possible genetic link between reconsolidation processes, fear conditioning and psychopathology. 
In addition to the reconsolidation effect on reacquisition, 5-HTTLPR short-allele carriers demonstrated slower extinction than the long-allele homozygotes. This is consistent with earlier studies reporting that short-allele carriers have delayed extinction. $^{12-14}$ The effect of the reconsolidation manipulation was evident in the short-allele carriers, but not in the longallele homozygotes. A previous cognitive behavioural treatment study of the post-traumatic stress disorder demonstrated better treatment effect in long-allele homozygotes as compared with the short-allele carriers. ${ }^{29}$ The present findings suggests that a joint combination of retarded extinction and enhanced renewal of fear in subjects carrying the short-allele may be responsible for the blunted treatment response.

Possible molecular mechanisms underlying the 5-HTTLPR effect include structural nervous-system changes during neonatal neural development, ${ }^{30}$ reflecting differences in grey matter volume, as well as altered functional connectivity of important structures in the emotional circuitry ${ }^{31,32}$ and differences in the amount of extracellular serotonin between short-allele and long-allele carriers, possibly affecting $5 \mathrm{HT} 1 \mathrm{~A}$ or 5HT6-receptors that have both been tied to memory consolidation processes. ${ }^{33-35}$ However, studies of whether 5-HTTLPR short-allele carriers actually have more or less extracellular serotonin in vivo have yielded mixed results. ${ }^{36-38}$

Dopamine seems vital for the acquisition of fear conditioning. For instance, dopamine is required in the nucleus accumbens and the basolateral amygdala for the formation of long-term fear memories, ${ }^{19}$ presumably because consolidation processes require dopamine. ${ }^{21}$ In the present study, the influence of the reconsolidation manipulation on reacquisition was evident for $\mathrm{val} / \mathrm{val}$ homozygotes, but not for the met carriers. Thus, val/val homozygotes maintain and update fear memories more effectively than met carriers supporting dopaminergic modulation of reconsolidation. The val/val homozygotes have an increased D1-receptor availability, likely resulting from the D1receptor upregulation caused by chronic low levels of dopamine ${ }^{25,39}$ Both D1 and D2 receptors have been associated with fear memory consolidation. ${ }^{40,41}$ However, the COMT polymorphism does not seem to alter cortical or striatal dopamine D2 receptor availability in vivo, ${ }^{42}$ suggesting that D1-receptor activity is a putative modulator of reconsolidation.

Moreover, because amygdala reactivity has been associated both with fear conditionability ${ }^{43}$ and a post-traumatic stress disorder diagnosis, ${ }^{44}$ and as both the 5 - HTTLPR $^{17}$ and the COMT polymorphism ${ }^{45-48}$ have been associated with amygdala activation, there may be a link between the amygdala reactivity and the observed reconsolidation effects.

There are some limitations to the present study. First, reinstatement data were compromised and could only be analysed for a minority of the participants. Second, as most of the homozygotes of the COMT val allele appeared among the 5-HTTLPR short-allele carriers, it is hard to disentangle the effect of one genotype from the other. However, as the 5-HTTLPR, but not the COMT, polymorphism affected extinction, and COMT, but not 5-HTTLPR, tended to affect acquisition, there is reason to believe that the genetic influence from the two polymorphisms stem from different molecular mechanisms. Finally, whether reacquisition is a process in which a new memory is formed, or a renewal of the original memory, cannot be determined here. Nevertheless, our results indicate that both the lasting expression of the original memory and renewal of fear through relearning are affected by reconsolidation processes.

In conclusion, this study demonstrates that human memory reconsolidation processes are influenced by serotonin and dopamine related genes.

\section{Conflict of interest}

The authors declare no conflict of interest.

Acknowledgements. This work was supported by the Swedish Research Council, the Swedish Council for Working Life and Social Research, and the Swedish Brain Foundation.

1. Milad MR, Orr SP, Lasko NB, Chang Y, Rauch SL, Pitman RK. Presence and acquired origin of reduced recall for fear extinction in PTSD: results of a twin study. J. Psychiatr Res 2008; 42: 515-520.

2. Mahan AL, Ressler KJ. Fear conditioning, synaptic plasticity and the amygdala: implications for posttraumatic stress disorder. Trends Neurosci 2011; 35: 1-12.

3. McGaugh JL. Memory-a century of consolidation. Science 2000; 287: 248-251.

4. Nader K, Hardt O. A single standard for memory: the case for reconsolidation. Nat Rev Neurosci 2009; 10: 224-234.

5. Soeter M, Kindt M. Disrupting reconsolidation: pharmacological and behavioral manipulations. Learn Mem 2011; 18: 357-366.

6. Kindt M, Soeter M, Vervliet B. Beyond extinction: erasing human fear responses and preventing the return of fear. Nat Neurosci 2009; 12: 256-258

7. Brunet A, Poundja J, Tremblay J, Bui E, Thomas E, Orr SP et al. Trauma reactivation under the influence of propranolol decreases posttraumatic stress symptoms and disorder: 3 open-label trials. J Clin Psychopharmacol 2011; 31: 547-550.

8. Monfils $\mathrm{M}-\mathrm{H}$, Cowansage KK, Klann E, LeDoux JE. Extinction-reconsolidation boundaries: key to persistent attenuation of fear memories. Science 2009; 324 : 951-955

9. Schiller D, Monfils M-H, Raio CM, Johnson DC, Ledoux JE, Phelps E. Preventing the return of fear in humans using reconsolidation update mechanisms. Nature 2010; 463: 49-53.

10. American Psychiatry Association. Diagnostic and Statistical Manual of Mental Disorders (DSM IV), 4th edn. American Psychiatric Press: Washington DC, 1994.

11. Hettema JM, Annas P, Neale MC, Kendler KS, Fredrikson M. A twin study of the genetics of fear conditioning. Arch Gen Psychiatry 2003; 60: 702-708.

12. Crişan LG, Pana S, Vulturar R, Heilman RM, Szekely R, Druğa B et al. Genetic contributions of the serotonin transporter to social learning of fear and economic decision making. Soc Cogn Affect Neurosci 2009; 4: 399-408.

13. Garpenstrand H, Annas P, Ekblom J, Oreland L, Fredrikson M. Human fear conditioning is related to dopaminergic and serotonergic biological markers. Behav Neurosci 2001; 115: 358-364

14. Lonsdorf TB, Weike Al, Nikamo P, Schalling M, Hamm AO, Ohman A. Genetic gating of human fear learning and extinction: possible implications for gene-environment interaction in anxiety disorder. Psychol Sci 2009; 20: 198-206.

15. Lesch KP, Bengel D, Heils A, Sabol SZ, Greenberg BD, Petri S et al. Association of anxiety-related traits with a polymorphism in the serotonin transporter gene regulatory region. Science 1996; 274: 1527-1531

16. Caspi A, Sugden K, Moffitt TE, Taylor A, Craig IW, Harrington H et al. Influence of life stress on depression: moderation by a polymorphism in the 5-HTT gene. Science 2003; 301: 386-389.

17. Hariri AR, Mattay VS, Tessitore A, Kolachana B, Fera F, Goldman D et al. Serotonin transporter genetic variation and the response of the human amygdala. Science 2002; 297: 400-403.

18. LeDoux J. The emotional brain, fear, and the amygdala. Cell Mol Neurobiol 2003; 23: $727-738$

19. Fadok JP, Darvas M, Dickerson TMK, Palmiter RD. Long-term memory for pavlovian fear conditioning requires dopamine in the nucleus accumbens and basolateral amygdala. PIOS ONE 2010; 5: e12751.

20. Mueller D, Bravo-Rivera C, Quirk GJ. Infralimbic D2 Receptors Are Necessary for Fear Extinction and Extinction-Related Tone Responses. Biol Psychiatry 2010; 68: 1055-1060

21. LaLumiere RT, Nawar EM, McGaugh JL. Modulation of memory consolidation by the basolateral amygdala or nucleus accumbens shell requires concurrent dopamine receptor activation in both brain regions. Learn Mem 2005; 12: 296-301.

22. Chen J, Lipska BK, Halim N, Ma QD, Matsumoto M, Melhem S et al. Functional analysis of genetic variation in catechol-O-methyltransferase (COMT): effects on 
mRNA, protein, and enzyme activity in postmortem human brain. Am J Hum Genet 2004; 75: 807-821.

23. Raczka K, Mechias M-L, Gartmann N, Reif A, Deckert J, Pessiglione M et al. Empirical support for an involvement of the mesostriatal dopamine system in human fear extinction. Translational Psychiatry 2011; 1: e12.

24. Boucsein W. Electrodermal activity. Plenum Press: New York, 1992.

25. Slifstein M, Kolachana B, Simpson EH, Tabares P, Cheng B, Duvall M et al. COMT genotype predicts cortical-limbic D1 receptor availability measured with [11C]NNC112 and PET. Mol Psychiatry 2008; 13: 821-827.

26. Johnson LC, Lubin A. On Planning Psychophysiological Experiments: Design, Measurement, and Analysis. In: Greenfield NS, Sternbach RA (eds). Handbook of Psychophysiology. Holt, Rinehart and Winston: New York, 1972, pp 125-153.

27. Lykken DT. Range correction applied to heart rate and to GSR data. Psychophysiology 1972; 9: 373-379.

28. Domschke K, Dannlowski U. Imaging genetics of anxiety disorders. Neuroimage 2010; 53 : 822-831.

29. Bryant R, Felmingham KL, Falconer EM, Pe Benito L, Dobson-Stone C, Pierce KD et al. Preliminary evidence of the short allele of the serotonin transporter gene predicting poor response to cognitive behavior therapy in posttraumatic stress disorder. Biol Psychiatry 2010; 67: 1217-1219.

30. Nordquist N, Oreland L. Serotonin, genetic variability, behaviour, and psychiatric disorders-a review. Ups J Med Sci 2010; 115: 2-10.

31. Pezawas L, Meyer-Lindenberg A, Drabant EM, Verchinski B, Munoz KE, Kolachana BS et al. 5-HTTLPR polymorphism impacts human cingulate-amygdala interactions: a genetic susceptibility mechanism for depression. Nat Neurosci 2005; 8: 828-834.

32. Selvaraj S, Godlewska BR, Norbury R, Bose S, Turkheimer F, Stokes P et al. Decreased regional gray matter volume in S' allele carriers of the 5-HTTLPR triallelic polymorphism. Mol Psychiatry 2011; 16: 472-473.

33. Ogren SO, Eriksson TM, Elvander-Tottie E, D'Addario C, Ekström JC, Svenningsson $P$ et al. The role of $5-\mathrm{HT}(1 \mathrm{~A})$ receptors in learning and memory. Behav Brain Res 2008; 195 54-77.

34. Foley AG, Murphy KJ, Hirst WD, Gallagher HC, Hagan JJ, Upton N et al. The 5-HT(6) receptor antagonist SB-271046 reverses scopolamine-disrupted consolidation of a passive avoidance task and ameliorates spatial task deficits in aged rats. Neuropsychopharmacology 2004; 29: 93-100.

35. Manuel-Apolinar L. 8-OH-DPAT facilitated memory consolidation and increased hippocampal and cortical cAMP production. Behav Brain Res 2004; 148: 179-184.

36. van Dyck CH, Malison RT, Staley JK, Jacobsen LK, Seibyl JP, Laruelle M et al. Measured With [123 I] $\beta$-CIT SPECT in Relation to Serotonin Transporter Genotype. Psychiatry: Interpersonal Biol Processes 2004; 161: 525-531.

37. Bah J, Lindström M, Westberg L, Mannerås L, Ryding E, Henningsson S et al. Serotonin transporter gene polymorphisms: effect on serotonin transporter availability in the brain of suicide attempters. Psychiatry Res 2008; 162: 221-229.
38. Shioe K, Ichimiya T, Suhara T, Takano A, Sudo Y, Yasuno F et al. No association between genotype of the promoter region of serotonin transporter gene and serotonin transporter binding in human brain measured by PET. Synapse 2003; 48: 184-188.

39. Guo N, Hwang D-R, Lo E-S, Huang Y-Y, Laruelle M, Abi-Dargham A. Dopamine depletion and in vivo binding of PET D1 receptor radioligands: implications for imaging studies in schizophrenia. Neuropsychopharmacology 2003; 28: 1703-1711.

40. Managò F, Castellano C, Oliverio A, Mele A, De Leonibus E. Role of dopamine receptors subtypes, D1-like and D2-like, within the nucleus accumbens subregions, core and shell, on memory consolidation in the one-trial inhibitory avoidance task. Learn Mem 2009; 16: 46-52.

41. Hikind N, Maroun M. Microinfusion of the D1 receptor antagonist, SCH23390 into the IL but not the BLA impairs consolidation of extinction of auditory fear conditioning. Neurobiol Learn Mem 2008; 90: 217-222.

42. Hirvonen MM, Någren $\mathrm{K}$, Rinne JO, Pesonen U, Vahlberg T, Hagelberg N et al. COMT Val158Met genotype does not alter cortical or striatal dopamine D2 receptor availability in vivo. Mol Imaging Biol 2010; 12: 192-197.

43. Furmark T, Fischer H, Wik G, Larsson M, Fredrikson M. The amygdala and individual differences in human fear conditioning. Neuroreport 1997; 8: 3957-3960.

44. Etkin A, Wager TD. Functional neuroimaging of anxiety: a meta-analysis of emotional processing in PTSD, social anxiety disorder, and specific phobia. Am J Psychiatry 2007; 164: $1476-1488$.

45. Rasch B, Spalek K, Buholzer S, Luechinger R, Boesiger P, de Quervain DJ-F et al. Aversive stimuli lead to differential amygdala activation and connectivity patterns depending on catechol-O-methyltransferase Val158Met genotype. Neuroimage 2010; 52 : 1712-1719.

46. Williams LM, Gatt JM, Grieve SM, Dobson-Stone C, Paul RH, Gordon E et al. COMT $\mathrm{Val}(108 / 158)$ Met polymorphism effects on emotional brain function and negativity bias. Neuroimage 2010; 53: 918-925.

47. Lelli-Chiesa G, Kempton MJ, Jogia J, Tatarelli R, Girardi P, Powell J et al. The impact of the Val158Met catechol-O-methyltransferase genotype on neural correlates of sad facial affect processing in patients with bipolar disorder and their relatives. Psychol Med 2011; 41: $779-788$

48. Domschke K, Ohrmann P, Braun M, Suslow T, Bauer J, Hohoff C et al. Influence of the catechol-O-methyltransferase val158met genotype on amygdala and prefrontal cortex emotional processing in panic disorder. Psychiatry Res 2008; 163: 13-20.

Translational Psychiatry is an open-access journal published by Nature Publishing Group. This work is licensed under the Creative Commons Attribution-Noncommercial-No Derivative Works 3.0 Unported License. To view a copy of this license, visit http://creativecommons.org/licenses/by-nc-nd/3.0/

\section{Supplementary Information accompanies the paper on the Translational Psychiatry website (http://www.nature.com/tp)}

